https://doi.org/10.48009/1_iis_2010_1-8

\title{
DEVELOPMENT AND DIFFUSION OF CUSTOMER RELATIONSHIP MANAGEMENT ACROSS DISCIPLINES: FAD OR FASHION?
}

\author{
Maria E. Barua, University of Texas at El Paso, mebarua@utep.edu \\ Godwin J. Udo, University of Texas at El Paso, gudo@utep.edu
}

\begin{abstract}
While the popularity of Customer Relationship Management has grown over the years and across disciplines, there is no clear consensus on how to define it. It also appears that different lifecycles exist of CRM depending on the discipline. This paper proposes a comprehensive definition of CRM that can be used across disciplines and uses bibliometirc technique to analyze the lifecycles of CRM in the Marketing and Information Systems disciplines for the purpose determining whether it is a fad or fashion. Results from a bibliometric technique, using data from 2000-2009, show the lifecycle of CRM appears to be a fad in the information systems and fashion in marketing fields. More study is needed to ascertain the popularity of the topic going forward.
\end{abstract}

Keywords: CRM, CRM Definition, Lifecycles, Fad or Fashion, Bibliometric Technique

\section{INTRODUCTION}

Challenging economic times and advances in technology have made today's consumer a different one. Consumers use online shopping, price comparison, coupons, and product reviews, to find the best products available, and they do not even think twice before switching brands. We see it in the communications industry where cell-phone providers engage in price-wars and heavy promotion, desperately trying to allure customers to switch companies only to see them leave when the next calling plan comes by. New strategies and processes are being employed to help the firm build long term relationships with each client and have their loyalty [25]. For companies to build long term relationships with consumers they must clearly understand the who, what, where and why of their customers and evaluate which customers are profitable and which customers are actually costing the company money. A business strategy that claims to aid in doing just that is Customer Relationship Management (CRM). While CRM has delivered benefits for many firms, there are those that see it as an unfulfilled promise that came and went like so many other management practices. CRM started to be noticed by both industry and academics in the early 1990's [15]. Although CRM's popularity grew across different business areas such as information systems (IS), marketing and business management, there is still no consensus on its operational definition; not even within each discipline. The CRM literature is inconsistent and highly fragmented mostly due to the lack of a common conceptualization [16, 29]. CRM is also criticized for having its programs failing seventy percent of the time [9], that is, not achieving the business objectives established. Researchers in information systems [20] and in the marketing disciplines [21] have tried to explain the factors that lead to CRM success or failure. Results find that failure has been associated with no clear objective for the tool or the lack of practical and technical competence to implement CRM properly [27]. Objectives cannot be clear if the understanding of CRM itself is not clear.

The purpose of this paper is two folds: (1) to come up with a common definition that can be applicable for research in the information systems (IS) and marketing disciplines, and allow the concept to grow then on from a common understanding of what it is and what is to be expected of it and (2) to investigate whether CRM is just another fad in research or if it is a fashion that will last. The first purpose is achieved using the guidelines by Gerring [10], which states that minimal definition can be formed from existing ones to allow the definition to be used across disciplines. The second purpose is achieved by applying Abrahamson's Management Fashion Theory, and bibliographic research model [2].

\section{THEORETICAL BACKGROUND}

\section{Customer Relationship Management Defined}

Economists were the first to propose the concept of value maximization where the firm can maximize profits and the customer can maximize utility. Today CRM is perceived as a value maximizing concept. CRM theorists define it as a tool for increasing firm performance and creating customer value [22]. Being a complex concept, CRM is often identified with a change in the corporate culture, that is, a shift from a 


\section{Development and Diffusion of Customer Relationship Management Across Disciplines}

transaction-focus to a relationship, customer-centered dimension directed at the individual rather than the group. CRM is based on relationship theory and satisfaction [21, 27] and hence defined as a shift in mindset from a product-centric to a customer-centric approach to business [21. So what is CRM? Due to the complexity of CRM, researchers and practitioners have defined CRM in terms of 1) software packages, processes, systems and technologies, 2) data systems, storage and analysis, 3) a change in corporate culture from a transactional focus to a relationship, customer-centered focus, that is, a new way of doing business with a powerful technology base useful for working with any and all relationships of the business, 4) a concept of managing demand, and 5) new strategy development for working with customers and others (identification, selection, acquisition, development, retention, etc.) [5]. Tanner [26] questions whether CRM is technology and software, a business strategy or a philosophy. Urbanskiene, et al. [27] consider it a business strategy and a multi-media device that integrates technology resources with customer-related business activities. Reinartz, Krafft and Hoyer [21] claim multiple definitions and dimensions including functional, firm-wide and customer facing.

Kincaid [13, p. 41] viewed CRM as "the strategic use of information, processes, technology, and people to manage the customer's relationship with your company (Marketing, Sales, Services, and Support) across the whole customer life cycle". Parvatiyar and Sheth [17, p. 5] defined CRM as "a comprehensive strategy and process of acquiring, retaining, and partnering with selective customers to create superior value for the company and the customer. It involves the integration of marketing, sales, customer service, and the supply-chain functions of the organization to achieve greater efficiencies and effectiveness in delivering customer value".

From IS and marketing perspectives, we combine and integrate various definitions and come up with a multi-facet definition of CRM similar to that of Zablah et al. [29]. CRM can be defined as (a) a business process that creates and leverages relationships with customers and other external marketplace entities; (b) a business strategy that invests in valuable customers; (c) a business philosophy that is customer-focus; (d) a business capability to understand the customers enough anticipate their future needs; and (e) a technologybased system for integrating sales, marketing, and services to build partnerships between the firm and its customers.

\section{Is CRM a Management Fad or Fashion?}

On top of not having a common agreed-upon definition, CRM's other problem is having ups and downs in academic and practitioner interest. Regardless of who leads who, or who really sets the next business model, we see in both academic research and business practice the arrival of management practices that become either fads or fashions. Abrahamson [2] suggests in his Theory of Management Fashion that management fashions are not necessarily created to fill the gaps in industry that are due to a change in the environment or technology. Instead, management fashions are created by sociopsychological forces such as managers collective tastes [1], excitement for a new practice, or mass conformity. In Baskerville's [6] study, findings reveal that information system research and practice, just as management research and practice, is indeed characterized by fads and fashions.

Management fashions have rapid bell-shaped swings in popularity [2]. The theory of management fashion is seen as largely a cultural phenomenon, "shaped by norms of rationality and progress" [2, p. 261].These norms of rationality suppose the development of a business technique that will be better than the one before it [6]. However, Abrahamson says that not all innovations are useful. In fact, some fashion innovations could damage a business [6]. Some exaggerated claims by a new "unique" management technique can result in fads that quickly go away and are evaluated as failures. Fads and fashions have been evaluated at times as useful, useless, trivial, with mass appeal or adopted by only a few [8].

Besides using neo-institutional theory (norms of rationality and progress), Abrahamson [1] also supports his theory on Roger's [23] theories of innovation and diffusion. The most well-known lifecycle shape is an S-curve, depicting an ideal representation for the emergence, growth, maturity, and decline of an idea or product [18]. Rogers [24] states however, that not all ideas and products exhibit an S-shaped lifecycle. Rogers [23] proposes that the adoption curve of innovations follows a normal distribution; however, fads and fashions have much shorter lifecycles. Fads become known quickly and are adopted with enthusiasm, sometimes fanaticism. The decline occurs just as fast [19]. Fashions on the other hand, are fads that show signs of maturity and later on end up declining [28].

Abrahamson and Fairchild [3] propose that downswings and upswings in management fashions in one research area remain independent of other management fashions coming into that area; that exogenous triggers affect management fashions 
independently. However, could it be that someone's fad is someone else's fashion? Could it be that CRM's lifecycle is different in IS than in marketing? Why? In his CRM literature review from 1992 to 2002, Ngai [16] found that $97 \%$ out of 205 articles that had been published up to that point had done so in only a three-year period between 2000 and 2002 . Furthermore, majority of the articles were published in IS publications. Even though CRM is a popular concept in marketing, nobody has done an analysis of articles that present CRM's lifecycle or diffusion in the marketing literature. It is our preposition that CRM is a popular topic in business research with more popularity in marketing than in IS literature. We further believe that what can be a fad in IS may be a fashion in marketing literature. We therefore present the following hypothesis:

H1: CRM research indicates a more
sustained growth in the marketing
literature than it does on the
information systems literature.
H2: $\quad$ CRM is in the maturity stage of its
lifecycle in marketing field
H3: $\quad$ CRM is a fad in information
systems research but a fashion in
marketing research

CRM is a multidisciplinary field of research; however, many see CRM as a management fad that in the majority of cases was unsuccessful in its implementation and results [21]. So why do we care if it is a fad or not? After businesses regard techiques (such as CRM) as a failed venture, the technique is quickly discontinued or left behind for limited use [18]. The status (fad/fashion) has implications for managers decisions regarding CRM programs as well as implications for research activities. In this study we analyze how research has presented CRM, as a fad or as a fashion in both the IS and marketing literature. While others have done research investigating management fads and fashions [2, 3, 6], the present research is different in that it compares the literatures of two disciplines (marketing and information systems) to determine if CRM has characteristics of both a fad and a fashion depending on the research area of choice. A search is done to capture all articles available in the database for a ten year period from 2000 to 2009. Also, this paper proposes a definition of the CRM construct that can be used across disciplines.

\section{METHODS}

How can we know if CRM is a fad or a fashion? One way is to quantify the number of published articles that have made reference to the concept. Ponzi [19] and Ponzi and Koenig [18] analyzed lifecycles and diffusion of innovations using bibliometric techniques. Article counting is a reliable method to investigate how a concept develops and its adoption and popularity [19. Management scientists like Chen, Chong and Tong [7] as well as management fashion theoreticians like Abrahamson [2] have agreed that bibliometric data collection is appropriate for analyzing lifecycles of innovations. For this research, the counts were based on the data entries in the Business Source Complete (EBSCO) database.

Ponzi and Koenig, [18] propose a bibliometric technique as an objective indicator for measuring the popularity, the diffusion of a concept. Bibliometric technique shows a graph with annual counts for articles that have been devoted to a certain concept over time. The initial result of the article-counting technique is time-series data that can show the concept's lifecycle [3]. For this paper, we compare the lifecycles of CRM in the IS literature to its lifecycle in the marketing literature from the year 2000 to 2009.

The top thirty-five journals from each discipline (IS and Marketing) were selected for the query that was done on December 20, 2009. The top 35 journals in the IS were identified as per the ranking of the Association for Information Systems (AIS). The top 35 journals in the marketing area were identified according to the findings of Hult, Reimann and Schilke [12] on worldwide faculty perceptions of marketing journals. See table 1 for rankings and number of articles in IS journals and table 2 for marketing journals.

The search query was done in three-steps to capture all the appropriate data from the year 2000 to 2009. The retrieved articles had 1) either "CRM" or "Customer Relationship Management" as part of their title, or 2) either "CRM" or "Customer Relationship Management" included in the subject terms provided by the author, or 3) either "CRM" or "Customer Relationship Management" included in the abstract of the paper. This procedure was done separately for the IS journals and for the Marketing journals (to include only the top journals identified previously).

\section{RESULTS}

After removing duplicates from the three queries, a total of 91 unique articles remained from the IS literature ranging from the year 2000 to 2009. A total of $184 \mathrm{CRM}$ articles have been published in the top marketing journals. We decided on this time period because our research revealed that CRM was not a common topic prior to 2000 at least in the marketing 
literature. It is important to note that Harvard Business Review appear $\mathrm{s}$ in both groups of journal list, therefore its thirteen articles appear in both counts (See table 1 and 2). If we were to take out Harvard Business Review from the lists, it would reduce the IS count by $14 \%$ and the marketing count by $7 \%$. While the trend would remain the same patterns, the graph would show a more significant separation between the first and second peaks in CRM popularity. On the other hand, there are four other top marketing journals that have more entries than Harvard Business Review, which only accounts for $7 \%$ of the total articles in the marketing literature (See table 2).

The results of the bibliometric technique show a greater number of articles being published in marketing literature than in the IS literature. With 185 articles published in top marketing journals and only 91 articles published in IS journals, $\mathrm{H} 1$ is supported by our results.

In figure 1, we see the number of articles and lifecycle of customer relationship management in the IS literature (top 35 journals) as listed in EBSCO database. It shows a pattern of peaks and valleys throughout its ten-year span. Each of the two peaks show a sudden increase and fall (lasting for less than four years) in popularity of CRM. These trends are similar to a managerial fad as explained by Abrahamson [1, 2].

The lifecycle of CRM articles in the marketing literature is shown in Figure 2 and follows a normal distribution as explained earlier in this paper. The lifecycle for articles in marketing has a closer look to a normal distribution and one lasting at least five years, therefore qualifying as a fashion rather than a fad. Regarding CRM's lifecycle stage in the marketing literature, it seems to be just at the point of being in the decline stage, no longer the maturity stage. Future studies can more accurately determine the stage by defining the turning point between maturity and decline and looking at the actual position of CRM in the next 5 to 10 years. Therefore, $\mathrm{H} 2$ is not supported which states that CRM is in the maturity stage of its lifecycle in the marketing field.

Table 1. Top 35 IS Journals \& CRM articles

\begin{tabular}{llll}
\cline { 2 - 3 } Ranking & IS Journals & Count & $\%$ age \\
\hline 1 & MIS Quarterly & 2 & $2 \%$ \\
2 & Info. Sys. Research & 0 & $0 \%$ \\
3 & Comm. of the ACM & 9 & $9 \%$ \\
4 & Journal of MIS & 2 & $2 \%$ \\
5 & Management Science & 5 & $5 \%$ \\
6 & Artificial Intelligence & 0 & $0 \%$
\end{tabular}

\begin{tabular}{|c|c|c|c|}
\hline 7 & Decision Sciences & 2 & $2 \%$ \\
\hline 8 & Harvard Bus. Rev. & 13 & $14 \%$ \\
\hline 9 & Euro. J. Info. Sys. & 1 & $1 \%$ \\
\hline 10 & Decision Sup. Sys. & 12 & $13 \%$ \\
\hline 11 & Info. \& Mgt. & 2 & $2 \%$ \\
\hline 12 & J. Comp.\& Sys. Sc. & 0 & $0 \%$ \\
\hline 13 & MIT Sloan Mgt Rev. & 9 & $9 \%$ \\
\hline 14 & Comm. of AIS & 9 & $9 \%$ \\
\hline 15 & INFORMS J. Com. & 0 & $0 \%$ \\
\hline 16 & ACM Trans D. S. & 0 & $0 \%$ \\
\hline 17 & Academy Mgt. J. & 0 & $0 \%$ \\
\hline 18 & Int. J. Elec. Comm. & 7 & $7 \%$ \\
\hline 19 & Journal of AIS & 1 & $1 \%$ \\
\hline 20 & Info. Sys. Frontiers & 0 & $0 \%$ \\
\hline 21 & Info. Sys. J. & 2 & $2 \%$ \\
\hline 22 & DB Adv. in IS & 0 & $0 \%$ \\
\hline 23 & Info. Systems & 0 & $0 \%$ \\
\hline 24 & Hu-Comp. Inter. & 0 & $0 \%$ \\
\hline 25 & Info. Tech. \& Peo. & 0 & $0 \%$ \\
\hline 26 & Cal. Mgt. Review & 3 & $3 \%$ \\
\hline 27 & J. Strategic IS & 0 & $0 \%$ \\
\hline 28 & J. Gl. Info. Tech. Mgt. & 0 & $0 \%$ \\
\hline 29 & Journal of CIS & 6 & $6 \%$ \\
\hline 30 & Info. \& Organization & 0 & $0 \%$ \\
\hline 31 & J. Information Tech. & 2 & $2 \%$ \\
\hline 32 & J. Info. Tech. (Rout.) & 0 & $0 \%$ \\
\hline 33 & J. Org. Comp\&eCom. & 3 & $3 \%$ \\
\hline 34 & Electronic Markets & 0 & $0 \%$ \\
\hline 35 & Behav. \& Info. Tech. & 6 & $6 \%$ \\
\hline TO & & 96 & $100 \%$ \\
\hline
\end{tabular}

Table 2. Top Marketing Journals \& CRM articles

\begin{tabular}{llll}
\cline { 2 - 4 } Rank & Marketing Journals & Count & $\%$ age \\
\hline 1 & Journal of Marketing & 17 & $9 \%$ \\
2 & J. Marketing Research & 1 & $1 \%$ \\
3 & J. Consumer Research & 0 & $0 \%$ \\
4 & Marketing Science & 5 & $3 \%$ \\
5 & J. Acad. Mkt. Sc. & 6 & $3 \%$ \\
6 & Harvard Bus Review & 13 & $7 \%$ \\
7 & Journal of Retailing & 1 & $1 \%$ \\
8 & Management Science & 6 & $3 \%$
\end{tabular}




\begin{tabular}{|c|c|c|c|}
\hline 9 & Intl. J. Res. Mkt. & 4 & $2 \%$ \\
\hline 10 & J. Consumer Psyc. & 0 & $0 \%$ \\
\hline 11 & Marketing Letters & 2 & $1 \%$ \\
\hline 12 & Adv. Cons. Res. & 6 & $3 \%$ \\
\hline 13 & J. Bus. Research & 8 & $4 \%$ \\
\hline 14 & Sloan Mgt Review & 1 & $1 \%$ \\
\hline 15 & J. Advertising & 4 & $2 \%$ \\
\hline 16 & Eur. J. Mkt. & 12 & $6 \%$ \\
\hline 17 & Psyc. \& Mkt. & 0 & $0 \%$ \\
\hline 18 & J. Pub. Pol. \& Mkt. & 0 & $0 \%$ \\
\hline 19 & J Service Research & 0 & $0 \%$ \\
\hline 20 & J Ad. Research & 0 & $0 \%$ \\
\hline 21 & J. Intl. Bus. Studies & 1 & $1 \%$ \\
\hline 22 & Indus. Mkt. Mgt. & 23 & $12 \%$ \\
\hline 23 & J. Prod. Inno. Mgt. & 4 & $2 \%$ \\
\hline 24 & Cal Mgt. Review & 3 & $2 \%$ \\
\hline 25 & J. Mkt. Mgt. & 8 & $4 \%$ \\
\hline 26 & J. Intl. Marketing & 0 & $0 \%$ \\
\hline 27 & J. Inter. Marketing & 0 & $0 \%$ \\
\hline 28 & Intl. Mkt. Review & 3 & $2 \%$ \\
\hline 29 & Journal of Business & 0 & $0 \%$ \\
\hline 30 & Quant. Mkt. \& Econ. & 0 & $0 \%$ \\
\hline 31 & Intl. J. Mkt. Research & 4 & $2 \%$ \\
\hline 32 & J. Bus-to-Bus Mkt. & 3 & $2 \%$ \\
\hline 33 & J. Bus. \& Ind. Mkt. & 13 & $7 \%$ \\
\hline 34 & J. Per. Sell\&Sales Mgt. & 17 & $9 \%$ \\
\hline 35 & Marketing Mgt. & 21 & $11 \%$ \\
\hline TOTAL & & 184 & $100 \%$ \\
\hline
\end{tabular}

Figure 1.- Lifecycle of CRM in IS Literature

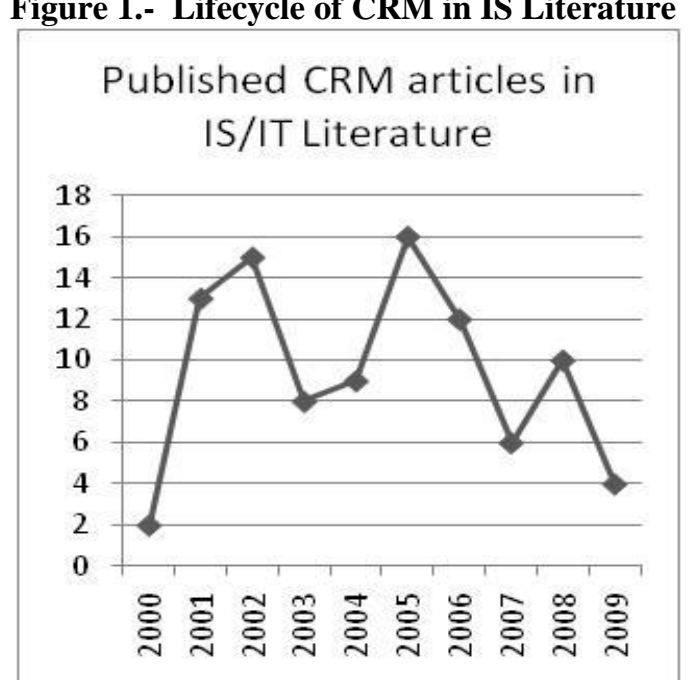

Volume XI, No. 1, 2010
Figure 3 compares the two groups. Looking at both lifecycles together in Figure 3, we can see that CRM has been more of a fad for IS discipline and a fashion for marketing. While there is a downward slope in the number of CRM articles in marketing over the past four years, the trend was on the upside between 2000 and 2005 which is clearly a fashion $[1,2]$ and in the case of IS discipline, the longest upward trend was only three years $(2003-2005)$, which is clearly a fad according to Abrahamson's theory $[1,2]$. This results support $\mathrm{H} 3$, which states that $\mathrm{CRM}$ is a fad in information systems research but a fashion in marketing research. In both cases, CRM was most popular in 2005 during the 10 years under review. In 2005, 13 articles were published in IS literature while over 30 articles were published in marketing literature.

Figure 2. Lifecycle of CRM in Mkt. Literature

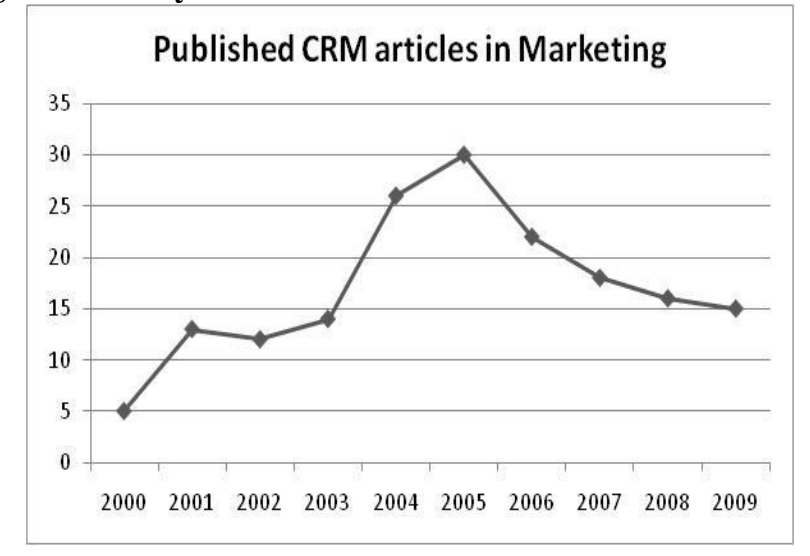

Figure 3. CRM Lifecycle: Marketing Vs IS Literature

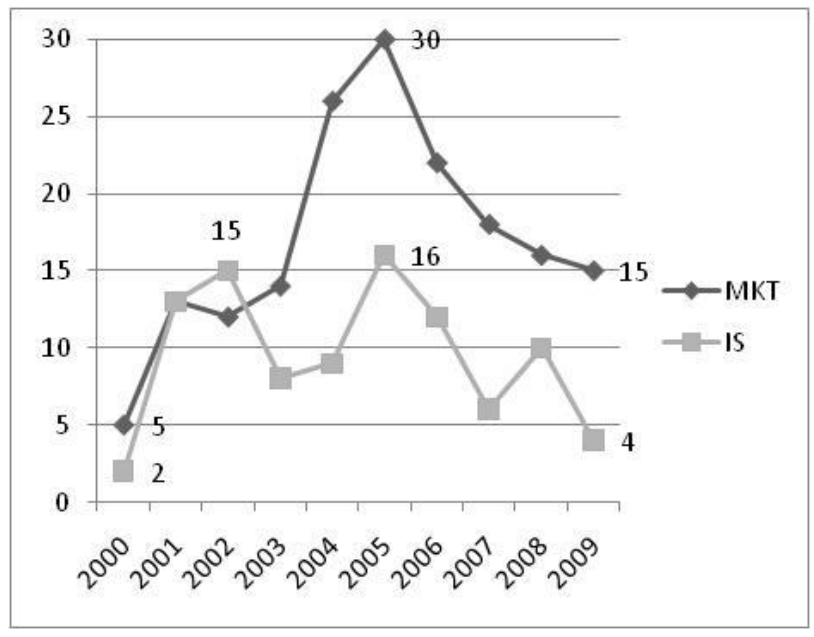




\section{CONCLUSIONS}

Customer Relationship Management has been the subject of research for well over ten years by both academia and industry. With a total of 275 articles published in the top marketing and IS journals between 2000 and 2009, CRM seems to be a management technique that draws interest across the board. However, between the two analyzed disciplines, research for CRM and CRM issues has been more consistent in marketing than in IS literature. CRM in marketing has established itself as a fashion as the number of published CRM-related articles has been on the rise for at least five years. The findings also reveals that the number of published CRM articles has been declining since 2005 in the marketing literature which calls for an investigation to determine if the topic is finally fading away or if it is just another cycle. Although there has been a decline on articles published on CRM over the last four years, the lowest point in marketing journals still surpasses the highest popularity point for CRM in IS literature. It will be interesting to see what the future holds for CRM, whether it is a long-lived fashion or even a permanent area in research.

Based on the results of this study, CRM behaves more as a fad in IS and as a fashion in marketing research. While IS research of CRM has seen ups and downs in popularity, its research in marketing has been greater in number and following the lifecycle characteristics of a fashion. It seems that marketing research has been able to embrace the concept of CRM and expand on it more so than IS. An example of this is the research being done in Customer Relationship Marketing, which is a strategy dependent on CRM technology and management. Given the proposed definition of CRM and the greater popularity of CRM in marketing journals, it can be concluded that CRM has a better fit and has been more popular in the marketing literature. A possible reason for this greater popularity could be because of greater marketing management and marketing strategy applications and as a consequence, greater number of research questions to be investigated. Although CRM is technologydriven, its applications and extensions seem to be greater in marketing areas such as strategy, sales, segmentation, customer satisfaction, customer loyalty, etc. The IS researchers seem to be less interested in CRM as a research topic since vendors have perfected and commercialize its development. There is also a debate on whether IS research in general is characterized mostly by fads. While there have been fashions described in IS research such as business process engineering, enterprise resource planning systems, and group decision support systems [6], researchers have found that IS researchers have been overly driven by new technological opportunities and research waves of "fads and fancies" [4, 14, 11]. On the other hand, studies have found that IS research closely parallels practice [6]. Studies are needed to investigate the reason behind these patterns, perhaps by understanding further the true nature of research and practice of information systems and technology.

Our study has a number of managerial and research implications. For managers, understanding the current state of CRM provides a reference point for the life of the innovation and may aid in implementation decisions. For academics, it also points out the popularity of the concept and how that may influence reviewers' decisions to accept or reject a paper in this research area.

\section{LIMITATIONS AND FUTURE RESEARCH}

While an extensive literature search was performed for the bibliometric study, some limitations exist. First, the search was limited to only one database source. Even though the chosen database (EBSCO) is regarded as one of the most complete and it includes all of the identified top journals in its database, other sources may have a different number of articles listed in their collection. Second, each article was not further analyzed to classify the extent of coverage of CRM. In other words, an analysis of how prominent was the discussion of CRM or if it was research as a component/basis for another concept was not performed. Third, the analysis includes just literature on the top 35 journals in IS and marketing. A study should be done to analyze CRM in other disciplines and smaller journals, as well as in other type of publications (trade, newspaper, private research).

The purpose of this research was to analyze the lifecycle of CRM in the academic literature. It would be interesting to analyze the content of the published articles, perhaps classifying them by IS and marketing subjects (i.e. sales, service and support, strategy, security, technology) and further analyze the status of CRM in each discipline. Also, future research can be done to analyze from which discipline are the authors of CRM articles. Perhaps there are just as many IS researchers as there are marketing researchers publishing on CRM issues, with the only difference being that more CRM articles are published in marketing journals. 
Another proposed research area is to continue analyzing the popularity of CRM in the future and compare its lifecycle to its popularity (lifecycle) in trade magazines or other media. We could then analyze if CRM is of similar interest to academics as it is to practitioners.

We believe there will be a resurgence of CRM in IS literature as issues such as security of database information and the use of CRM in social networks sites emerges as a key concern in businesses. Other real-world business issues that need to be researched are open-source CRM, e-commerce and retail industry using CRM, loyalty programs such as in the hotel and airline industry, implementation of all CRM tools, and impact of CRM on business performance.

\section{REFERENCES}

1. Abrahamson, E. (1991). Managerial fads and fashions: The diffusion and rejection of innovations. The Academy of Management Review, 16(3), 586-612.

2. Abrahamson, E. (1996). Management fashion. The Academy of Management Review, 21(1), 254-285.

3. Abrahamson, E. and Fairchild, G. (1999). Management fashion: Lifecycles, triggers, and collective learning processes. Administrative Science Quarterly, 44, 708740 .

4. Banville, C., and Landry, M. (1989). Can the field of MIS be disciplined? Communications of the ACM, 32(1, 48-61.

5. Baran, R. J., Galka, R. J., and Strunk, D. P. (2008). Principles of customer relationship management. Mason, OH: Thomson SouthWestern.

6. Baskerville, R.L. (2009). Fashion waves in information systems research and practice. MIS Quarterly, 33(4), 647-662.

7. Chen, Y., Chong, P. P., and Tong, M. Y. (1994). The Simon-Yule approach to bibliometric modeling, Information Processing \& Management, 30, 535-556.

8. Donaldson, L., and Hilmer, F. G. (1998). Management redeemed: The case against fads that harm management. Organizational Dynamics. 26(4), 6-20.

9. Dyché, J. (2002). The CRM handbook: a business guide to customer relationship management. Boston: Addison Wesley.

10. Gerring, J. (2001). Social science methodology: A criterial framework. Cambridge, New York: Cambridge University Press.
11. Gregor, S., and Jones, D. (2007). The anatomy of a design theory. Journal of the Association for Information Systems, 8(5), 312-335.

12. Hult, G. T., Reimann, M. and Schilke, O. (2008). Worldwide faculty perceptions of marketingjJournals: Rankings, trends, comparisons, and segmentations. Global Edge Business Review 3(3), 1- 23.

13. Kincaid, J.W. (2003). Customer relationship management: Getting it right!. Prentice-Hall PTR, Upper Saddle River, NJ.

14. Landry, M., and Banville, C. (1992). A disciplined methodological pluralism for MIS research. Accounting, Management and Information Technologies, 2(2), 77-97.

15. Ling, R. and Yen, D.C. (2001). Customer relationship management: an analysis framework and implementation strategies. Journal of Computer Information Systems, 41(3), 82-97.

16. Ngai, E.W.T. (2005). Customer relationship management research (1992-2002) An academic literature review and classification. Marketing Intelligence and Planning, 23(6), 582-605.

17. Parvatiyar, A. and Sheth, J.N. (2001). Customer relationship management: emerging practice, process, and discipline. Journal of Economic \& Social Research, 3(2), 1-34.

18. Ponzi, L. and Koenig, M. (2002). Knowledge management: another management fad? Information Research, 8(1), 145.

19. Ponzi, L.J. (2002). The intellectual structure and interdisciplinary breadth of knowledge management: A bibliometric study of its early stage of development. Akadémiai Kiadó. 55(22), 259-272.

20. Ray, G., Muhanna, W.A. and Barney, J.B. (2005). Information technology and the performance of the customer service process: A resource-based analysis. MIS Quarterly 29(4), 625-652.

21. Reinartz,W., Krafft, M. and Hoyer, W.D. (2004). The customer relationship management process: Its measurement and impact on performance. Journal of Marketing Research, 41(3), 293-305.

22. Rogers, M. (2005). Customer strategy: Observations from the trenches. Journal of Marketing, (69), 262-63.

23. Rogers, E.M. (1983). Diffusion of Innovation $\left(2^{\text {nd }}\right.$. ed.), New York: Free Press. 
24. Rogers, E.M. (1995). Diffusion of innovation (4th ed.), New York: Free Press.

25. Sanchez, J. (2005). Customer Relationship Marketing, Journal of Marketing Research

26. Tanner, J.F., Ahearne, M., Leigh, W.L., Mason, C.H. and Moncrief, W.C. (2005). CRM in sales-intensive organizations: A review and future directions. Journal of Personal Selling and Sales Management, 25(2), 170-180.

27. Urbanskiene, R., Zostautiene, D., and Chreptaviciene, V. (2008). The model of creation of customer relationship management (CRM) system. Engineering Economics, 51-59.

28. Wasson, C. (1978). Dynamic competitive strategy and product life cycles. Austin, TX: Austin Press.

29. Zablah, A.R., Bellenger, D.N. and Johnston, W.J. (2004). An evaluation of divergent perspectives on customer relationship management: Towards a common understanding of an emerging phenomenon. Industrial Marketing Management, 33(6), 475-489. 